\title{
Deficiência Visual nas Crianças Indígenas em Idade Escolar das Etnias Guarani e Kaiowá na Região da Grande Dourados/ MS: Um EsTUdo SObre A INCIDÊNCIA E AS NECESSIDADES EsPecíficAS E EDUCACIONAIS ESPECIAIS Visual Impairment on School-Age Children of Guarani and KaiowÁ Communities of Grande Dourados, MS: A Study about Incidence and SPECIFIC EDUCATIONAL NeEDS
}

\author{
Michele Aparecida de $S A^{1}$ \\ Marilda Moraes Garcia BRUNO²
}

\begin{abstract}
RESUMO: Pesquisas sobre deficiência visual nas populaçōes indígenas das etnias Guarani e Kaiowá são escassas. O objetivo geral deste estudo consistiu em mapear a deficiência visual entre os escolares indígenas da Região da Grande Dourados, MS. Os objetivos específicos foram: identificar os escolares indígenas com baixa visão e cegueira nas escolas indígenas; caracterizar as causas da deficiência visual nessa população; descrever as necessidades específicas e educacionais especiais dos escolares indígenas com deficiência visual. Os procedimentos para coleta de dados foram: observação de campo e triagem ocular de seis mil escolares; avaliação oftalmológica, funcional da visão, das necessidades específicas e educacionais especiais dos escolares identificados. Os resultados indicaram alta incidência de deficiência visual entre a população estudada: nove cegos, dos quais quatro não têm acesso à educação; dos sete com baixa visão, três estão fora da escola; um deles apresenta deficiência múltipla. As causas prevalentes foram atrofia óptica e alteração retiniana. As avaliaçôes apontam adequaçóes relativas: distância de discriminação de objetos, gravuras, obstáculos; compensação do campo visual para locomoção e atividades diárias; adaptação de materiais pedagógicos quanto aos contrastes, tamanho de letras, cores e o controle da iluminação; necessidades de recursos ópticos especiais e não ópticos. Concluise que a efetivação do direito à saúde e à educação entre os escolares indígenas é ignorada pelo poder público, observa-se múltipla negação de direitos: a combinação da pobreza com a deficiência, a falta de acesso à saúde ocular e ao Atendimento Educacional Especializado.
\end{abstract}

PALAVRAS-CHAVE: Educação Especial. Deficiência visual. Educação Indígena.

\begin{abstract}
Research on visual impairment among Guarani and Kaiowá indigenous populations is scarce. The general objective of this study consisted of mapping and identifying visual impairment of indigenous students of the Grande Dourados region, Mato Grosso do Sul (MS). The specific objectives were: to select and evaluate indigenous students who were visually impaired or had blindness; to uncover the causes of visual disabilities in this population; to describe specific educational special needs of visually impaired students. The data collection procedures were: field observation and ocular triage of six thousand students; ophthalmologic, functional evaluation of vision, and also of specific and educational needs of students that had been identified. Results point to a high incidence of visual impairment in the studied population: nine blind, of which four have no access to education; three among seven with low vision capacity are not in school; another student presents multiple disabilities. The prevalent causes are optic atrophy and retinal changes. The evaluations point to some adjustments: distance for the identification of objects, pictures, obstacles; compensation of the visual field for locomotion and daily activities; adaptation of pedagogical materials related to contrast, letter size, colors and lighting control; requirements of special optical and non-optical resources. It is possible to conclude that the effectiveness of the right to education and health for these students is neglected by public authorities; there is multiple denial of rights: given the combination of poverty and disability, there was no access to eye health or specialized educational services.
\end{abstract}

KEYWORDS: Special Education. Visual Disability. Indigenous Education.

\footnotetext{
${ }^{1}$ Mestre em Educação - UFGD e doutoranda em Educação Especial - UFSCar. micheledesa20@hotmail.com

${ }^{2}$ Doutora em Educação pela UNESP de Marília. Docente da Faculdade de Educação e do Programa de Pós-graduação em Educação, UFGD e líder do Grupo de Estudos e Pesquisa em Educação Inclusiva - GEPEI. mgbruno@uol.com.br
} 


\section{INTRODUÇÁo}

No Brasil, nas últimas décadas, o debate sobre a formulação de políticas públicas afirmativas tem se intensificado. $\mathrm{O}$ ordenamento jurídico brasileiro fundamenta-se nos princípios do direito do homem, nos quais todas as pessoas são sujeitos de direito: direito à educaçáo, à saúde, ao lazer, à participação e à autonomia. Sob esses princípios, diversos movimentos sociais reivindicam a efetivação da educação em todos os níveis e a inclusão escolar a todos os segmentos sociais, inclusive à população indígena, objeto deste estudo.

Atualmente, as políticas de educaçẫo estão voltadas para educar todos os alunos independente de suas condiçóes sociais, étnicas, intelectuais ou físicas. A proposta de inclusão educacional de alunos com deficiência no sistema regular de ensino assegura respostas às necessidades específicas e educacionais especiais no cotidiano escolar. Para tanto, torna-se fundamental que essas necessidades sejam adequadamente identificadas.

As ações de identificação, prevenção e a intervenção pedagógicas para minimizar as possíveis dificuldades de aprendizagem entre escolares com deficiência estáo previstas no Plano Nacional de Educação Lei no ${ }^{\circ}$ 10.172/2001 (BRASIL, 2001), quando orienta a ampliação do atendimento educacional e dos serviços de Educação Especial, para a identificação das alterações no processo de desenvolvimento, e a implementação de medidas de prevenção das deficiências na infância.

A deficiência visual divide-se em dois grupos: cegueira e baixa visão. A cegueira é definida pelo Conselho Internacional de Oftalmologia (2002) como a perda total da visão e é também considerada nos casos em que o indivíduo se utiliza, de forma predominante, dos recursos de substituição da visão. Baixa visão é descrita por Sampaio e Haddad (2010) como a condição da função visual entre visão normal e cegueira, secundária a um acometimento irreversível da visão, na qual a correção dos erros de refração não é suficiente para a melhora da resolução visual.

Na perspectiva educacional, Bruno (2001) informa que a baixa visão é uma alteração da capacidade funcional da visão, decorrente de inúmeros fatores isolados ou associados, sendo eles: baixa acuidade visual significativa, redução importante do campo visual, alteraçôes corticais ou de sensibilidade aos contrastes que interferem ou limitam o desenvolvimento visual do indivíduo. A autora concebe a cegueira como perda total da visão até a ausência de projeção de luz e cita a necessidade do sistema braile para leitura e escrita e a utilização dos outros sentidos (tátil-cinéstico, auditivo, olfativo) para o processo de desenvolvimento da aprendizagem.

Com relação à incidência da deficiência visual, dados da Organização Mundial da Saúde (OMS), baseados na população mundial de 2002, estimam que mais de 161 milhóes de pessoas possuam a deficiência visual, das quais 124,264 milhóes teriam baixa visão e 36,857 milhóes seriam cegas (HADDAD; SAMPAIO, 2010). De acordo com OMS (2004), no Brasil, considera-se a estimativa da prevalência de cegueira em $0,3 \%$ e de baixa visão em $1,7 \%$ na população geral. Na população infantil, é estimada a prevalência de cegueira em $0,062 \%$ da população até 15 anos de idade; assim, a cegueira na infância é responsável por 6,4\% dos casos de cegueira no país. 
Alves e Kara-José (2000) estimam que cerca de 20\% de crianças em idade escolar apresentam dificuldades visuais devido a defeitos refracionais não corrigidos, estrabismo, ambliopia, entre outros. Em cada 1.000 alunos do ensino fundamental, 100 são portadores de erros de refração, necessitando de óculos para a correção de hipermetropia, miopia e astigmatismo. Desses, aproximadamente 5\% apresentam redução de acuidade visual, menos de $50 \%$ da visão normal.

Dados de 2009 do Conselho Brasileiro de Oftalmologia (CBO) revelam que 30\% das crianças brasileiras em idade escolar apresentam problemas de refração, o que equivale dizer que diversos alunos passam por dificuldades de aprendizagem devido a problemas visuais não diagnosticados e não corrigidos. Com relação às casuísticas da deficiência visual na infância, ela é ocasionada especialmente em decorrência de fatores nutricionais, infecciosos e falta de tecnologia, pelo fato dessas crianças viverem em países em desenvolvimento (HADDAD; SAMPAIO, 2010).

Em levantamento realizado no banco de dissertaçóes e teses da Coordenação de Aperfeiçoamento de Pessoal de Nível Superior (CAPES), constatou-se a escassez de estudos acerca da detecção da deficiência visual em crianças indígenas em idade escolar. No campo da baixa visão, pesquisadores enfatizam a importância da avaliação das funçóes visuais na primeira infância (ALVES; KARA-JOSÉ, 2000; GASPARETO, 2001, 2007; BRUNO, 2001, 2005; HADDAD, 2006; HADDAD; SAMPAIO, 2010). Esses autores recomendam ação conjunta nas áreas da saúde e da educação para garantir que as necessidades específicas decorrentes da deficiência visual sejam atendidas.

Assim, o objetivo geral da pesquisa foi mapear a deficiência visual entre escolares indígenas Guarani e Kaiowá da Região da Grande Dourados, MS. Os objetivos específicos resultaram em: identificar os escolares indígenas com baixa visão e cegueira nas escolas indígenas; caracterizar as causas da deficiência visual nessa população; descrever as necessidades específicas e educacionais especiais dos escolares indígenas com deficiência visual.

A sustentação desta investigação fundamenta-se nos princípios teóricos de autores como Edgar Morin (2003) e Bronfenbrenner (1996), que ajudam a entender a interdependência entre as diferentes áreas e instâncias envolvidas na implementação de políticas públicas e açóes que contemplam as necessidades e a pluralidade dos homens.

\section{Método}

Para realizar o mapeamento e a identificação da deficiência visual foi realizado um levantamento prévio sobre o número de aldeias indígenas de Dourados e região, além do número de crianças matriculadas nas escolas indígenas, da distância a ser percorrida até chegar às aldeias e das condiçóes das estradas.

Delimitadas as cidades e as escolas para o mapeamento e a identificação da deficiência visual, realizou-se um estudo piloto por meio de oficinas para os professores de algumas escolas indígenas participantes da pesquisa. $\mathrm{O}$ objetivo dessas oficinas foi possibilitar conhecimentos relativos à identificação das deficiências, reconhecer os sintomas e sinais de problemas oculares e a adequação dos procedimentos para a aplicação do teste de acuidade visual (Escala Optométrica de Snellen, ou teste do "E”). As oficinas possibilitaram a adequação da avaliação 
à cultura indígena e foram ofertadas em dois períodos aos professores das escolas indígenas nas cidades de Dourados, Caarapó e Douradina.

\subsection{EsCOLHA, ELABORAÇÃo E APLICAÇÃo DOS INSTRUMENTOS DE AVALIAÇÃo}

Este momento resultou na elaboração de dois Protocolos. O primeiro, destinado à identificação da deficiência visual e de problemas de refração ocular com base nas especificidades da população indígena. Este Protocolo teve por objetivos coletar dados pessoais, escolares, além daqueles referentes à função visual: acuidade visual, sinais e sintomas de alterações visuais. $\mathrm{O}$ segundo resultou num pequeno manual de orientação aos professores para realizarem a triagem ocular de escolares.

Para a triagem, foi elaborado um pequeno Kit de avaliação, contendo: cinco Tabelas de Snellen, dois optotipos de cartolina preta para oclusão, lápis preto, substituição da fita métrica por barbante contendo diferentes medidas; pasta plástica com os protocolos de avaliação.

As escolas que não participaram das oficinas receberam o manual com os procedimentos para a aplicação do teste de acuidade visual e cinco tabelas (Escala Optométrica de Snellen) para que os professores aplicassem o teste com seus respectivos alunos. Também foram distribuídas as fichas para a identificação da deficiência visual e possíveis erros de refração. Os professores preencheram a ficha para posterior reavaliação realizada pela equipe da pesquisa (mestranda pesquisadora e orientadora).

\subsection{Triagem Ocular}

A triagem ocular contou com a colaboração de alguns professores indígenas e alunos do nono ano treinados pela equipe avaliadora. Quando era identificado algum caso de acuidade visual muito reduzida, ele era anotado na ficha de identificação da deficiência visual para, posteriormente, ser reavaliado por testes específicos para baixa visão. Assim, após a avaliação e a identificação da alteração visual dos alunos, suas fichas foram arquivadas em pastas, por aldeia, para posterior encaminhamento ao oftalmologista.

A utilização da Escala Optométrica de Snellen para triagem ocular da população indígena apresentou dificuldade quanto ao item de indicaçáo da letra E para os lados direito e esquerdo. Observou-se que esse conceito não se faz presente e útil no contexto das aldeias. Alguns escolares preferiram a própria mão (os menores), e os maiores utilizaram a letra em cartão para indicação da posição.

\subsection{Avaliaçáo Oftalmológica Geral e Especializada em Baixa Visáo}

Após o levantamento dos escolares para consulta oftalmológica, foram contatados os postos da Fundação Nacional de Saúde (FUNASA) e as Secretarias Municipais de Educação, que autorizaram e colaboraram com o transporte dos escolares e familiares à Dourados. Esta etapa foi subdividida em dois momentos: avaliação oftalmológica geral e especializada em Baixa Visão. O primeiro deles, a avaliação oftalmológica geral para diagnóstico clínico e avaliação de refração e orientação para tratamentos. Pontua-se que os dois procedimentos foram realizados de forma voluntária pelos oftalmologistas colaboradores. 
A avaliação oftalmológica especializada para identificação da baixa visão, orientação de recursos ópticos, habilitação ou reabilitação visual foi realizada pela professora da Universidade de São Paulo (USP), oftalmologista do Setor de Visão Subnormal do Hospital das Clínicas de São Paulo, uma vez que o estado de Mato Grosso do Sul não possui oftalmologista especializado em Baixa Visão.

As escalas e testes utilizados para acuidade visual foram: Tabela Low Vision (2005) para perto e Longe com letras, números e E; LIGTHHOUSE Letters (1959) e Teste para Leitura da UNICAMP (1990). Destaca-se que para as crianças pequenas e para as não alfabetizadas foram utilizados os Testes LIGHT HOUSE SYMBOL (1976) e LVRC Distance visual Acuity Test (1972). As tabelas foram posicionadas a distância maior de dois metros até $0,8 \mathrm{~cm}$.

Foi solicitado para a consulta oftalmológica o acompanhamento de familiares e de um professor para esclarecimentos e orientaçóes quanto aos procedimentos a serem adotados.

\subsubsection{AVAliaÇÃo FUNCIONAL da VISÃo E dAS NECESSIDADES ESPECÍfICAS E EDUCACIONAIS}

As avaliaçóes (funcional da visão e das necessidades específicas) dos alunos identificados como baixa visão foram, num primeiro momento, realizadas nas escolas indígenas e, posteriormente, os escolares identificados foram reavaliados pela pesquisadora com a supervisão da orientadora deste estudo, no Hospital Porta da Esperança, na Missão Evangélica Caiuá, em Dourados, antes da avaliação oftalmológica geral.

As observaçóes realizadas foram relativas: a esfera visual, teste cores, contraste, identificação de gravuras, números e letras. Os testes utilizados nesta etapa foram: Tabela Lighthouse Symbol (1976) e Bust Card (testes compostos por figuras do cotidiano: colher, garfo, faca, óculos, copo, casa, maçã, guarda-chuva) (1976). Cabe pontuar que algumas crianças identificaram a figura da maçã como tomate, cuja resposta foi considerada correta. Após todas as observações, os alunos tiveram seus olhos dilatados para o exame oftalmológico geral.

O referencial teórico utilizado para a observação dos aspectos relativos às necessidades específicas e à adaptação do meio foi a perspectiva sociocultural de Bronfenbrenner (1996), que orienta a participação de professores e da família no processo de avaliação. Nessa perspectiva, a avaliação foi realizada por meio do ludodiagnóstico, visto que a ação da criança sobre os objetos e a forma como elas brincam podem revelar seus pontos fortes, suas possibilidades e necessidades de apoio (BRUNO, 2005).

Os procedimentos de avaliação foram adaptados para a realidade e a cultura da criança indígena, com situaçóes, atividades e objetos significativos que partissem da experiência e da vivência cotidiana dessas crianças. Os brinquedos selecionados foram: sapos, aranhas, peixes, lagartos, chocalho maracá e bolas para substituir os bonecos, avióes e navios. Para os que apresentavam dificuldades para visão de detalhes e cegueira, foram utilizados utensílios de alimentação existentes nas escolas: colher, copo e prato, além dos materiais escolares.

A avaliação funcional da visão compreendeu observar o comportamento visual do aluno em termos de funçôes visuais básicas (percepção de luz, movimento, objeto, cores e contrastes), funções viso-motoras (fixação, seguimento visual e coordenação olho-mão) e funções viso-perceptivas (discriminação de cores, formas, figuras, letras e números). 
A identificação das necessidades específicas de alunos indígenas com baixa visão envolveu a identificação da esfera visual (distância de discriminação de cores, objetos, gravuras e obstáculos), a identificação do tamanho de gravura, letra e a distância que o aluno consegue ler de perto e de longe (atividades na lousa), a necessidade de ampliação de letras e textos, a verificação do campo visual útil para leitura e escrita de perto e cópia da lousa, o uso da visão para a locomoção, atividades diárias e jogos e a modificação dos contrastes e o controle da iluminação para melhor visualização. Observou-se ainda a necessidade de iluminação e adaptação dos recursos pedagógicos.

Após esses procedimentos, os professores foram orientados quanto ao atendimento das necessidades específicas e educacionais especiais de cada aluno avaliado.

\section{Resultado e Discussóes}

Neste estudo, foi realizada a triagem ocular em mais de 6.000 escolares das escolas indígenas, distribuídas em 10 municípios localizados na Região da Grande Dourados, como é possível observar na tabela a seguir:

Tabela 1 - Número de alunos triados

\begin{tabular}{|l|c|c|}
\hline CIDADE & ESCOLA & TOTAL DE ALUNOS \\
\hline \multirow{4}{*}{ Dourados } & Escola A & 496 \\
\cline { 2 - 3 } & Escola B & 489 \\
\cline { 2 - 3 } & Escola C & 400 \\
\cline { 2 - 3 } & Escola D & 1250 \\
\cline { 2 - 3 } & Escola E & 854 \\
\cline { 2 - 3 } & Escola F & 28 \\
\hline Bela Vista & Escola G & 56 \\
\hline Caarapó & Escola H & 720 \\
\hline Douradina & Escola I & 140 \\
\hline Maracajú & Escola J & 56 \\
\hline Eldorado & Escola $\mathrm{K}$ & 125 \\
\hline \multirow{3}{*}{ Japorã } & Escola L & 350 \\
\cline { 2 - 3 } & Escola M & 240 \\
\cline { 2 - 3 } & Escola N & 80 \\
\hline Ponta Porá & Escola O & 35 \\
\hline \multirow{2}{*}{ Amambai } & Escola P & 686 \\
\cline { 2 - 3 } & Escola Q & 320 \\
\hline Paranhos & Escola $\mathrm{R}$ & 140 \\
\hline Antonio João & Escola S & 150 \\
\hline TOTAL & & $\mathbf{6 6 1 8}$ \\
\hline
\end{tabular}

Fonte: Escolas Indígenas

Os escolares indígenas participantes do mapeamento estavam cursando os anos iniciais e finais do Ensino Fundamental. A idade dos participantes encontra-se distribuída na faixa-etária de seis a 21 anos. 
Em virtude da grande maioria desses escolares não terem passado anteriormente por triagem ocular, foram encontrados casos de erro de refração. Do total de escolares triados, 6.618, 210 apresentaram algum tipo de alteração de acuidade visual (erros de refração).

De uma forma geral, os achados da triagem ocular indicam bom desempenho visual na faixa etária estudada. O percentual de 96,5\% de escolares apresenta padróes visuais acima da média, com acuidade visual de 20/20. De acordo com dados do Conselho Brasileiro de Oftalmologia (1998), 20\% dos escolares apresentam dificuldades visuais. Neste estudo, a triagem ocular entre escolares indígenas revelou que do total de escolares estudados apenas 3,5\% apresentavam alteraçóes visuais, ou seja, com relação aos padrões nacionais, o percentual de escolares indígenas com algum tipo de erro de refração é menor.

No reteste, com instrumentos adequados à baixa visão, foram encontradas 68 pessoas com suspeita de deficiência visual. Das 68 pessoas que passaram pelo oftalmologista, oito delas tiveram a prescrição imediata do uso de óculos para correção de refração e duas foram encaminhadas para cirurgia, como é o caso de uma criança do Centrinho ${ }^{3}$, que tem glaucoma congênito, e de uma menina de Amambai, que perfurou o olho com um galho de árvore.

A tabela abaixo apresenta a amostra das cidades, das escolas, o número de alunos e a incidência de alteração da acuidade visual e possíveis erros de refração.

Tabela 2 - Escolares com alteração de acuidade visual

\begin{tabular}{|c|c|c|c|c|}
\hline \multirow{2}{*}{ CIDADE } & \multirow{2}{*}{ ESCOLA } & \multirow{2}{*}{ NÚMERO DE ALUNOS } & \multicolumn{2}{|c|}{ ACUIDADE VISUAL } \\
\hline & & & $0,4-0,6$ & $0,7-0,8$ \\
\hline \multirow{6}{*}{ Dourados } & Escola A & 496 & & \\
\hline & Escola B & 489 & & 05 \\
\hline & Escola C & 400 & & \\
\hline & Escola D & 1250 & 03 & 03 \\
\hline & Escola E & 854 & 01 & 02 \\
\hline & Escola F & 28 & 02 & \\
\hline Bela Vista & Escola G & 56 & & \\
\hline Caarapó & Escola $\mathrm{H}$ & 720 & 02 & \\
\hline Antonio Joáo & Escola I & 150 & 06 & 04 \\
\hline Douradina & Escola J & 140 & 01 & 02 \\
\hline Maracajú & Escola $\mathrm{K}$ & 56 & & \\
\hline Eldorado & Escola L & 125 & & \\
\hline \multirow{3}{*}{ Japorã } & Escola M & 350 & 02 & 01 \\
\hline & Escola N & 240 & & \\
\hline & Escola O & 80 & & \\
\hline Ponta Porã & Escola P & 35 & & 03 \\
\hline \multirow[t]{2}{*}{ Amambai } & Escola Q & 686 & 03 & 03 \\
\hline & Escola R & 320 & & \\
\hline Paranhos & Escola $S$ & 140 & 01 & 01 \\
\hline TOTAL & & 6618 & 21 & 24 \\
\hline
\end{tabular}

Fonte: Dados do presente estudo

3 O Centrinho corresponde a uma ala do hospital Porta da Esperança, localizado na Missão Evangélica Caiuá, situada na cidade de Dourados. O Centrinho atende crianças indígenas do sul de Mato Grosso do Sul que estâo em situação de severa desnutrição. 
O número de escolares indígenas com possíveis erros de refração, com alteração da acuidade visual entre 0,4 e 0,6, resulta num total de 21 escolares. Haddad (2006) pontua que esta acuidade visual é significativa e pode dificultar no processo de ensino-aprendizagem quando esses erros de refração não são corrigidos. Dados da OMS (2002) revelam que uma das maiores causas que provocam deficiência visual entre a população mundial está relacionada à não correção dos erros de refração. Dourados apresentou o maior número de escolares com alteração da acuidade visual, fato que pode estar relacionado ao maior número de escolares indígenas avaliados.

\subsection{INCIDÊNCIA DA DEFICIÊNCIA VISUAL ENTRE ESCOLARES INDÍGENAS}

Nesta seção serão apresentados os dados referentes à incidência da deficiência visual entre crianças e jovens indígenas. Os resultados fazem parte da avaliação oftalmológica especializada em baixa visão. A tabela a seguir indica a quantidade de escolares e o tipo de deficiência visual encontrado nas escolas indígenas.

Tabela 3 - Escolares com deficiência visual

\begin{tabular}{|c|c|c|c|c|}
\hline \multirow{2}{*}{ CIDADE } & \multirow{2}{*}{ ESCOLA } & \multirow{2}{*}{$\begin{array}{l}\text { NÚMERO DE } \\
\text { ALUNOS }\end{array}$} & \multicolumn{2}{|c|}{ DEFICIÊNCIA VISUAL } \\
\hline & & & Baixa Visão & Cegueira \\
\hline \multirow{6}{*}{ Dourados } & Escola A & 496 & - & - \\
\hline & Escola B & 489 & & 01 \\
\hline & Escola C & 400 & 02 & 01 \\
\hline & Escola D & 1250 & 01 & - \\
\hline & Escola E & 854 & - & - \\
\hline & Escola F & 28 & & \\
\hline Bela Vista & Escola G & 56 & - & - \\
\hline Caarapó & Escola $\mathrm{H}$ & 720 & & \\
\hline Antonio João & Escola I & 150 & - & 01 \\
\hline Douradina & Escola J & 140 & - & 01 \\
\hline Maracajú & Escola K & 56 & - & - \\
\hline Eldorado & Escola L & 125 & - & - \\
\hline \multirow{3}{*}{ Japorã } & Escola M & 350 & - & - \\
\hline & Escola N & 240 & - & 01 \\
\hline & Escola O & 80 & - & - \\
\hline Ponta Porá & Escola P & 35 & - & - \\
\hline \multirow[t]{2}{*}{ Amambai } & Escola Q & 686 & - & - \\
\hline & Escola R & 320 & - & - \\
\hline Paranhos & Escola $S$ & 140 & 01 & - \\
\hline $\begin{array}{l}\text { Alunos que não } \\
\text { frequentam escolas }\end{array}$ & & & $03^{*}$ & $04^{*}$ \\
\hline TOTAL & & 6618 & 07 & 09 \\
\hline
\end{tabular}

Fonte: Dados do presente estudo

* A pedido da comunidade indígena, foram avaliados crianças e adolescentes que nâo frequentavam a escola. 
Observa-se que a incidência de deficiência visual entre escolares indígenas é considerada alta quando comparada aos dados da OMS (2004). Segundo pesquisa da OMS, no Brasil, considera-se a estimativa da prevalência de cegueira em $0,062 \%$ da população até 15 anos de idade, e nos escolares estudados, a prevalência ficou em 0,15\%.

Dos jovens e crianças identificados com deficiência visual nas 19 escolas indígenas contempladas com a triagem ocular e com as avaliaçóes oftalmológicas especializadas, foram encontrados 16 casos de deficiência visual, dos quais nove eram cegos e sete possuíam baixa visão. No município de Dourados, foram encontrados cinco casos (três com baixa visão e dois cegos) concentrados em três escolas, ou seja, possui 31,25\% dos casos de deficiência visual triados. Neste município, os estudos de Brand (1998), Graciano (2004) e Souza (2008) demonstram que as condiçóes de saúde e saneamento básico são precárias, o alcoolismo e o uso de drogas é constante e a gravidez na adolescência está presente no cotidiano desta população.

Neste contexto, observa-se que a questão da deficiência visual na população indígena em idade escolar no município de Dourados se insere num campo conflituoso. "Isso significa que abandonamos um tipo de explicação linear por um tipo de explicação em movimento, circular, em que vamos da parte para o todo e do todo para a parte" (MORIN, 2003, p. 182) (princípio holográmatico). Os escolares com deficiência visual identificados neste estudo representam, enquanto parte, as contradiçôes existentes na sociedade, ou seja, a falta de atuação das áreas da saúde, educação e das políticas públicas.

\subsection{Resultado da aValiação oftalmológica especializada em Baixa Visão}

A seguir, serão apresentados os dados relativos à identificação da deficiência visual entre crianças e jovens indígenas. Os dados fazem parte dos resultados da avaliação oftalmológica especializada em Baixa Visão, realizada após a triagem ocular na escola e seguida pela avaliação oftalmológica geral. O quadro abaixo indica os municípios de incidência, o tipo de deficiência, a idade, o sexo, os índices de acuidade visual e as causas da perda visual.

Quadro 1- Identificação da deficiência visual entre escolares indígenas

\begin{tabular}{|l|l|l|l|c|l|l|}
\hline \multirow{4}{*}{ MUNICÍPIO } & $\begin{array}{l}\text { TIPO DE } \\
\text { DEFICIÊNCIA } \\
\text { VISUAL }\end{array}$ & ALUNO* & CASUÍSTICA & IDADE & SEXO & A.V \\
\hline \multirow{5}{*}{ Baixa visão } & Ana & Cicatriz macular & 17 & Fem. & $\begin{array}{l}\text { O.D: } 20 / 840 \\
\text { O.E: } 20 / 1000\end{array}$ \\
\cline { 2 - 7 } & Baixa visão & Fernanda & $\begin{array}{l}\text { Alta miopia e astig- } \\
\text { matismo }\end{array}$ & 14 & Fem. & $\begin{array}{l}\text { O.D: } 20 / 120 \\
\text { O.E: } 20 / 240\end{array}$ \\
\cline { 2 - 7 } & Baixa visão & Julia & $\begin{array}{l}\text { Hipoplasia de nervo } \\
\text { óptico }\end{array}$ & 11 & Fem. & $\begin{array}{l}\text { O.D: } \text { NI } \\
\text { O.E: } 20 / 200\end{array}$ \\
\cline { 2 - 7 } & Cegueira & Mariana & - & 17 & Fem. & --- \\
\cline { 2 - 7 } & Cegueira & Joni & Distrofia retiniana & 12 & Masc. & $\begin{array}{l}\text { OD } \\
\text { OE* } 20 / 200\end{array}$ \\
\cline { 2 - 7 } & Cegueira & Carlos & $\begin{array}{l}\text { Nistagmo Atrofia } \\
\text { NO }\end{array}$ & 03 & Masc. & $\begin{array}{l}\text { OD PV } \text { PV }^{* *} \\
\text { OE PL* }\end{array}$ \\
\hline
\end{tabular}




\begin{tabular}{|c|c|c|c|c|c|c|}
\hline & Cegueira & Antonio & $\begin{array}{l}\begin{array}{l}\text { Glaucoma Congê- } \\
\text { nito }\end{array} \\
\end{array}$ & 03 & Masc. & $\begin{array}{l}\text { OD PV } \\
\text { OE PL }\end{array}$ \\
\hline Caarapó & $\begin{array}{l}\text { Cegueira } \\
\text { Cegueira } \\
\end{array}$ & $\begin{array}{l}\text { Pedro } \\
\text { José } \\
\end{array}$ & $\begin{array}{l}\text { Atrofia ótica- } \\
\text { Atrofia óptica }\end{array}$ & $\begin{array}{l}16 \\
17 \\
\end{array}$ & $\begin{array}{l}\text { Masc. } \\
\text { Masc. }\end{array}$ & $\begin{array}{l}\text { Não informa } \\
\text { Não informa }\end{array}$ \\
\hline Antonio João & $\begin{array}{l}\text { Cegueira } \\
\text { DI }\end{array}$ & Sonia & $\begin{array}{l}\text { Catarata congênita } \\
\text { Descolamento de } \\
\text { retina }\end{array}$ & 13 & Fem. & $\begin{array}{l}\text { OD PL e PV } \\
\text { OE NI }\end{array}$ \\
\hline Douradina & Cegueira & André & Trauma ocular & 10 & Masc. & $\mathrm{NI}$ \\
\hline Japorã & Cegueira & Denis & $\begin{array}{l}\text { Hipoplasia de nervo } \\
\text { óptico }\end{array}$ & 08 & Mas. & $\begin{array}{l}\text { OD OE PL } \\
\text { PV }\end{array}$ \\
\hline \multirow[t]{2}{*}{ Rio Brilhante } & Baixa visão & Isa & $\begin{array}{l}\text { Alteração macular } \\
\text { (despigmentação) }\end{array}$ & 10 & Fem. & $\begin{array}{l}\text { O.D: } 20 / 80 \\
\text { O.E: } 20 / 60 \\
\end{array}$ \\
\hline & Baixa visão & Tamires & $\begin{array}{l}\text { Distrofia retiniana e } \\
\text { lesão macular }\end{array}$ & 03 & Fem. & - \\
\hline \multirow[t]{2}{*}{ Paranhos } & Baixa Visão & Luiz & $\begin{array}{l}\text { Atrofia e palidez de } \\
\text { nervo óptico. }\end{array}$ & 19 & Masc. & - \\
\hline & Baixa visão & Gustavo & $\begin{array}{l}\text { Fundo de olho } \\
\text { albino. }\end{array}$ & 03 & Masc. & - \\
\hline
\end{tabular}

* Para preservar a identidade das crianças e jovens foram utilizados nomes fictícios.

** OD (olho direito); OE (olho esquerdo); NI (não informa); PL (percepção de luz); PV (percepção de vulto); PC (percepção de contraste).

A idade das pessoas diagnosticadas com deficiência visual variou entre três e 19 anos, com distribuição equitativa entre os sexos masculino (oito casos) e feminino (oito casos). $\mathrm{O}$ que se destaca neste estudo é a alta prevalência de cegueira, 16 casos, dos quais nove não eram diagnosticados. Esta é uma incidência preocupante, pois os dados da OMS para os países em desenvolvimento indicam a prevalência de uma pessoa cega em cada três mil e uma com baixa visão para cada grupo de quinhentas pessoas (BRUNO, 2001).

As patologias de maior prevalência entre a população indígena estudada foram atrofia óptica (seis), disfunçôes retinianas (quatro), corioretinite (um), catarata congênita (um), glaucoma (um), trauma ocular (um) e alta miopia com astigmatismo (um). A literatura relata que as principais causas da atrofia óptica podem ser desnutrição da gestante, da criança, anóxia peri-natal, processos infecciosos, substâncias tóxicas, como álcool, veneno e drogas em geral (HADDAD; SAMPAIO, 2010).

\subsection{Resultados das Avaliaçóes das Necessidades Específicas e Educacionais Espe- CIAIS}

As necessidades específicas das pessoas com deficiência visual são entendidas aqui como aquelas que dizem respeito às necessidades peculiares decorrentes da condição de deficiência de cada um, e podem ser diferentes até nas mesmas condiçóes visuais e patológicas. Elas referem-se às necessidades permanentes na vida do sujeito, em diferentes ambientes: em casa, na escola e na comunidade (BRUNO, 2007). 
Neste contexto, Bronfenbrenner (1996) informa que a ecologia do desenvolvimento humano envolve estudos científicos da acomodação progressiva, mútua, entre o ser humano ativo, em desenvolvimento, e as propriedades mutantes dos ambientes imediatos em que a pessoa em desenvolvimento vive, conforme esse processo é afetado pelas relaçóes entre esses ambientes e pelos contextos mais amplos em que os ambientes estáo inseridos.

Para a compreensão das necessidades específicas, o diagnóstico oftalmológico especializado tornou-se fundamental também para o esclarecimento das possíveis causas, do tipo de perda visual, bem como para a realização dos encaminhamentos necessários e a prescrição de recursos ópticos e/ou auxiliares para a compensação da perda visual.

De forma semelhante, a avaliação funcional da visão e das necessidades específicas foi imprescindível para o entendimento de todas as ajudas possíveis para a melhoria da resolução visual, do processo de aprendizagem, da interação, da comunicaçáo, da independência e da qualidade de vida desses alunos.

O protocolo avaliaçáo funcional da visão organizado por Bruno (2005) mostrouse útil para compreender as habilidades visuais básicas, viso-motoras e viso-perceptivas dos escolares. A forma de avaliar por meio de atividades lúdicas e atividades naturais do cotidiano foi compatível com o perfil da população investigada.

A avaliação das Funçôes Visuais Básicas (reação à luz, a cores, à forma, a pessoas, a objetos, ao contato visual) e a avaliação do campo visual foram importantes e necessárias para a compreensão das possibilidades visuais de interaçáo com pessoas e meio, bem como para a modificação do ambiente e arranjo dos materiais que deverão ser utilizados na escola.

A seguir são apresentados os resultados da avaliação das necessidades específicas decorrentes da Baixa Visão entre escolares indígenas da regiấo da Grande Dourados.

Quadro 2 - Necessidades específicas decorrentes da Baixa Visão

\begin{tabular}{|l|l|l|l|l|l|l|}
\hline ALUNO & $\begin{array}{l}\text { ESFERA } \\
\text { VISUAL }\end{array}$ & $\begin{array}{l}\text { CAMPO } \\
\text { VISUAL }\end{array}$ & CONTRASTE & ILUMINAÇÃO & $\begin{array}{l}\text { RECURSOS } \\
\text { ÓPTICOS }\end{array}$ & $\begin{array}{l}\text { RECURSOS } \\
\text { DE APOIO }\end{array}$ \\
\hline Luiz & --- & $\begin{array}{l}\text { Restrito } \\
\text { CVC* }\end{array}$ & $\begin{array}{l}\text { Vermelho preto } \\
\text { Branco }\end{array}$ & $\begin{array}{l}\text { Alta iluminaçáo } \\
\text { Dirigida }\end{array}$ & Lupas manuais & $\begin{array}{l}\text { EV com alto } \\
\text { contraste }\end{array}$ \\
\hline Gustavo & $40 \mathrm{~cm}$ & $\begin{array}{l}\text { CVE* alte- } \\
\text { rado }\end{array}$ & $\begin{array}{l}\text { Preto } \\
\text { Branco } \\
\text { Filtro amarelo }\end{array}$ & Baixa iluminação & $\begin{array}{l}\text { Óculos com } \\
\text { lentes filtrantes }\end{array}$ & $\begin{array}{l}\text { EV } \\
\text { Figuras c/ } \\
\text { contrastes }\end{array}$ \\
\hline Tamires & $08 \mathrm{~cm}$ & $\begin{array}{l}\text { Prefere } \\
\text { CVE }\end{array}$ & Altos contrastes & $\begin{array}{l}\text { Objetos } \\
\text { Iluminados }\end{array}$ & $\begin{array}{l}\text { EV integraçáo } \\
\text { sensorial }\end{array}$ \\
\hline Isa & $1 \mathrm{~m}$ & Cores fluores- \\
centes & $\begin{array}{l}\text { Iluminação } \\
\text { Dirigida } \\
\text { Boa iluminação } \\
\text { natural }\end{array}$ & $\begin{array}{l}\text { Ampliação de } \\
\text { figuras e letras } \\
\text { contrastes }\end{array}$ \\
\hline Fernanda & $\begin{array}{l}\text { OE } 1 \mathrm{~m} \\
\text { OD } 15 \mathrm{~cm} \\
\text { P/ perto } \\
30 \mathrm{~cm}\end{array}$ & CVE & Alto contrastes & $\begin{array}{l}\text { Boa iluminação } \\
\text { natural }\end{array}$ & $\begin{array}{l}\text { Ampliação } \\
\text { Figuras e } \\
\text { letras }\end{array}$ \\
\hline
\end{tabular}




\begin{tabular}{|l|l|l|l|l|l|l|}
\hline Ana & Perto $30 \mathrm{~cm}$ & CVE & $\begin{array}{l}\text { Potencializar } \\
\text { Contrastes }\end{array}$ & $\begin{array}{l}\text { Iluminação } \\
\text { natural }\end{array}$ & $\begin{array}{l}\text { Óculos 15 } \\
\text { dioptrias }\end{array}$ & --- \\
\hline
\end{tabular}

* CVC (Campo visual central); CVE (Campo visual esquerdo); CVP (Campo visual periférico).

Portanto, as principais necessidades específicas encontradas na população estudada foram variação da distância de discriminação, objetos, gravuras e obstáculos; compensação do campo visual para locomoção e atividades diárias; modificação do ambiente e materiais pedagógicos quanto a contrastes, tamanho de letras, cores e o controle da iluminação para melhor visualização.

As necessidades educacionais especiais foram observadas na avaliação funcional do aluno e por meio de observaçáo na escola, para que sejam atendidas no contexto da sala de aula. Foram concebidas como o tipo de resposta educativa, de recursos e apoios que a escola deve proporcionar para que o aluno obtenha sucesso na aprendizagem (BRUNO, 2005).

A avaliação na perspectiva sociocultural ecológica, conforme orienta Bronfenbrenner (1996), foi útil porque priorizou as inter-relaçóes das crianças com as pessoas e com o seu ambiente natural. As avaliaçóes ocorreram nas escolas (no microssistema das crianças), preocupando-se com o processo de interação e comunicação na língua indígena, com um professor intérprete da língua Guarani-kaiowá que participou de todas as etapas de triagem e avaliação.

Os resultados das avaliaçóes das necessidades educacionais especiais serão descritos conforme as condiçóes visuais dos educandos avaliados e de acordo com o impacto e as implicaçóes dessas no processo de aprendizagem dos escolares indígenas com deficiência visual. Os dados serão organizados e sistematizados de forma a visualizar as possibilidades, as necessidades, os tipos de recursos especiais e os apoios necessários à promoção da aprendizagem dos escolares avaliados.

Quadro 3 - Necessidades educacionais especiais de escolares cegos e com baixa visão

\begin{tabular}{|l|l|l|l|l|l|l|}
\hline Aluno & CC* & $\begin{array}{l}\text { Estratégias } \\
\text { Didáticas }\end{array}$ & $\begin{array}{l}\text { Recursos Tecno- } \\
\text { lógicos }\end{array}$ & $\begin{array}{l}\text { Recursos } \\
\text { Especiais }\end{array}$ & $\begin{array}{l}\text { Adaptaçáo } \\
\text { de material }\end{array}$ & Apoios \\
\hline Antonio & IP*RBC & $\begin{array}{l}\text { Trabalho em conjun- } \\
\text { to com a família }\end{array}$ & & $\begin{array}{l}\text { Brinquedos } \\
\text { Sensoriais } \\
\text { Objetos ilumi- } \\
\text { nados }\end{array}$ & $\begin{array}{l}\text { Contraste } \\
\text { Preto branco }\end{array}$ & $\begin{array}{l}\text { Fisio e } \\
\text { fono }\end{array}$ \\
\hline Carlos & IP RBC & $\begin{array}{l}\text { Trabalho em conjun- } \\
\text { to com a família }\end{array}$ & $\begin{array}{l}\text { Brinquedos } \\
\text { Sensoriais } \\
\text { Objetos ilumi- } \\
\text { nados }\end{array}$ & $\begin{array}{l}\text { Vermelho } \\
\text { preto branco }\end{array}$ & $\begin{array}{l}\text { Fisio e } \\
\text { Fono }\end{array}$ \\
\hline Denis & $\begin{array}{l}\text { Braile } \\
\text { OM* } \\
\text { AVP* }\end{array}$ & $\begin{array}{l}\text { AD* } \\
\text { Adequaçáo das } \\
\text { Atividades e avaliaçăo }\end{array}$ & $\begin{array}{l}\text { Computador } \\
\text { Leitor tela }\end{array}$ & $\begin{array}{l}\text { Máquina braile } \\
\text { Livro falado }\end{array}$ & $\begin{array}{l}\text { Jogos Brinque- } \\
\text { dos } \\
\text { Sensoriais }\end{array}$ & Bengala \\
\hline $\begin{array}{l}\text { Braile } \\
\text { OM } \\
\text { AVP }\end{array}$ & $\begin{array}{l}\text { AD } \\
\text { Adequação das } \\
\text { Atividades e avaliaçáo }\end{array}$ & $\begin{array}{l}\text { Computador } \\
\text { Leitor tela }\end{array}$ & $\begin{array}{l}\text { Máquina braile } \\
\text { Livro falado }\end{array}$ & $\begin{array}{l}\text { Jogos, mapas } \\
\text { adaptados }\end{array}$ & Bengala \\
\hline
\end{tabular}




\begin{tabular}{|c|c|c|c|c|c|c|}
\hline André & $\begin{array}{l}\text { Braile } \\
\text { OM } \\
\text { AVP }\end{array}$ & $\begin{array}{l}\text { AD } \\
\text { Adequação das } \\
\text { Atividades avaliação }\end{array}$ & $\begin{array}{l}\text { Computador } \\
\text { Leitor tela }\end{array}$ & $\begin{array}{l}\text { Máquina braile } \\
\text { Livro falado }\end{array}$ & $\begin{array}{l}\text { Jogos e } \\
\text { Mapas } \\
\text { Adaptados }\end{array}$ & Bengala \\
\hline Joni & $\begin{array}{l}\text { OM } \\
\text { AVP }\end{array}$ & $\begin{array}{l}\text { Comunicação } \\
\text { Tátil } \\
\text { Adequação das } \\
\text { Atividades e avaliação }\end{array}$ & $\begin{array}{l}\text { Computador } \\
\text { Leitor tela }\end{array}$ & $\begin{array}{l}\text { Maquina } \\
\text { Braile }\end{array}$ & $\begin{array}{l}\text { Jogos e } \\
\text { Mapas } \\
\text { Adaptados }\end{array}$ & $\begin{array}{l}\text { Guia intér- } \\
\text { prete }\end{array}$ \\
\hline Mariana & $\begin{array}{l}\text { Braile } \\
\text { OM } \\
\text { AVP }\end{array}$ & $\begin{array}{l}\text { AD } \\
\text { Adequação das } \\
\text { Atividades e avaliação }\end{array}$ & $\begin{array}{l}\text { Computador } \\
\text { Leitor tela }\end{array}$ & $\begin{array}{l}\text { Máquina braile } \\
\text { Livro falado }\end{array}$ & $\begin{array}{l}\text { Jogos e } \\
\text { Mapas } \\
\text { Adaptados }\end{array}$ & Bengala \\
\hline José & $\begin{array}{l}\text { Braile } \\
\text { OM } \\
\text { AVP }\end{array}$ & $\begin{array}{l}\text { AD } \\
\text { Adequação das } \\
\text { Atividades e avaliação }\end{array}$ & $\begin{array}{l}\text { Computador } \\
\text { Leitor tela }\end{array}$ & $\begin{array}{l}\text { Livro falado } \\
\text { Máquina braile }\end{array}$ & $\begin{array}{l}\text { Jogos } \\
\text { Adaptados }\end{array}$ & Bengala \\
\hline Pedro & $\begin{array}{l}\text { Braile } \\
\text { OM } \\
\text { AVP }\end{array}$ & $\begin{array}{l}\text { AD } \\
\text { Adequação das } \\
\text { Atividades e avaliação }\end{array}$ & $\begin{array}{l}\text { Computador } \\
\text { Leitor tela } \\
\text { Livro falado }\end{array}$ & $\begin{array}{l}\text { Livro falado } \\
\text { Máquina braile }\end{array}$ & $\begin{array}{l}\text { Jogos e } \\
\text { Adaptados }\end{array}$ & Bengala \\
\hline Gustavo & $40 \mathrm{~cm}$ & $\begin{array}{l}\text { Objetos tridimen- } \\
\text { sionais } \\
\text { Histórias } \\
\text { Figuras s/detalhes c/ } \\
\text { contrastes }\end{array}$ & $\begin{array}{l}\text { Lupa eletrônica } \\
\text { Figuras } \\
\text { Futura alfabeti- } \\
\text { zação }\end{array}$ & $\begin{array}{l}\text { Filtro amarelo } \\
\text { Porta texto }\end{array}$ & $\begin{array}{l}\text { Jogos infantis } \\
\text { adaptados }\end{array}$ & \\
\hline Tamires & $\begin{array}{l}\mathrm{IP} \\
\mathrm{RCB}^{*}\end{array}$ & $\begin{array}{l}\text { Trabalho em conjun- } \\
\text { to com a família }\end{array}$ & & $\begin{array}{l}\text { Brinquedos } \\
\text { Sensoriais } \\
\text { Objetos ilumi- } \\
\text { nados }\end{array}$ & $\begin{array}{l}\text { Livros e jogos } \\
\text { Sensoriais }\end{array}$ & Bengala \\
\hline Isa & AVP & $\begin{array}{l}\text { Adequação da } \\
\text { Atividade e avaliação }\end{array}$ & $\begin{array}{l}\text { Computador } \\
\text { Fonte } 16\end{array}$ & $\begin{array}{l}\text { Lupa manual } \\
4 \mathrm{D} \\
\text { Guia leitura }\end{array}$ & $\begin{array}{l}\text { Texto ampliado } \\
\text { Fonte } 16 \\
\text { Pautas amplia- } \\
\text { das }\end{array}$ & Porta texto \\
\hline Julia & $\begin{array}{l}\text { Uso fun- } \\
\text { cional } \\
\text { Da visão } \\
\text { AVP }\end{array}$ & $\begin{array}{l}\text { Adequação da } \\
\text { Atividade e avaliação }\end{array}$ & $\begin{array}{l}\text { Computador } \\
\text { Fonte } 18\end{array}$ & $\begin{array}{l}\text { Lupa manual } \\
\text { 6D } \\
\text { Guia leitura }\end{array}$ & $\begin{array}{l}\text { Texto ampliado } \\
\text { c/ contraste } \\
\text { Pautas amplia- } \\
\text { das }\end{array}$ & Porta texto \\
\hline $\begin{array}{l}\text { Fernan- } \\
\text { da }\end{array}$ & $\begin{array}{l}\text { Uso fun- } \\
\text { cional } \\
\text { Da visão } \\
\text { AVP }\end{array}$ & $\begin{array}{l}\text { Adequação da } \\
\text { Atividade e avaliação }\end{array}$ & $\begin{array}{l}\text { Computador } \\
\text { Fonte } 40\end{array}$ & $\begin{array}{l}\text { Lupa manual } \\
12 \mathrm{D} \\
\text { Guia leitura }\end{array}$ & $\begin{array}{l}\text { Texto ampliado } \\
\text { Fonte } 40 \\
\text { Contraste } \\
\text { Pautas amplia- } \\
\text { das }\end{array}$ & Porta texto \\
\hline Ana & $\begin{array}{l}\text { Uso fun- } \\
\text { cional } \\
\text { Da visão } \\
\text { AVP } \\
\end{array}$ & $\begin{array}{l}\text { Adaptação } \\
\text { da Atividade e } \\
\text { avaliação }\end{array}$ & $\begin{array}{l}\text { Computador } \\
\text { Fonte } 60\end{array}$ & $\begin{array}{l}\text { Lupa p/ figuras e } \\
\text { letras }\end{array}$ & $\begin{array}{l}\text { Livros e jogos } \\
\text { Sensoriais } \\
\text { Pautas amplia- } \\
\text { das } \\
\end{array}$ & Porta texto \\
\hline Luiz & $\begin{array}{l}\text { Uso fun- } \\
\text { cional } \\
\text { da visão } \\
\text { Braile }\end{array}$ & $\begin{array}{l}\text { Adequação da } \\
\text { Atividade e avaliaçáo }\end{array}$ & $\begin{array}{l}\text { Computador } \\
\text { fonte ampliada } \\
\text { Fonte } 60\end{array}$ & Luminária & $\begin{array}{l}\text { Figuras e letras } \\
\text { alto } \\
\text { Contraste } \\
\text { Preto branco } \\
\text { Pautas amplia- } \\
\text { das }\end{array}$ & Porta texto, \\
\hline
\end{tabular}

* CC (Complementação curricular); OM (Atividades de orientação e mobilidade); AVP (Atividades de vida prática); AD (Audiodescrição); IP (Intervenção Precoce)

As principais necessidades educacionais especiais encontradas na população estudada resultaram na adaptaçáo e na adequação das atividades e avaliação em sala de aula; uso de 
computador com leitor de tela ou fonte ampliada, máquina braile; material didático ampliado ou em braile; caderno com pauta ampliada e porta texto.

\section{Consideraçótes Finais}

As análises dos dados indicaram alta incidência da deficiência visual entre escolares indígenas quando comparada aos dados da OMS (2004). Essa pesquisa indica que no Brasil a estimativa da prevalência de cegueira em $0,062 \%$ na população até 15 anos de idade. Entre os escolares estudados, a prevalência ficou em $0,15 \%$.

Os resultados da avaliação oftalmológica especializada para orientação e encaminhamento escolar apontaram que as patologias de maior prevalência na população indígena estudada foram: atrofia óptica (seis casos), disfunçóes retinianas (quatro casos). Ressalta-se que estes achados merecem ser estudados para se obter mais detalhes sobre a casuística da deficiência visual nessa população.

Os resultados indicam que as principais necessidades específicas dos escolares com baixa visão são relativas: variação da distância de discriminação de objetos, gravuras e obstáculos; compensação do campo visual para locomoção e atividades diárias; modificação do ambiente e materiais pedagógicos quanto aos contrastes, tamanho de letras, cores e o controle da iluminação para melhor visualização, e necessidades de recursos ópticos especiais e não ópticos.

A avaliação Funcional da Visão, das necessidades específicas e educacionais especiais, contribuiu para a compreensão das possibilidades dos escolares, de suas dificuldades visuais, identificação das barreiras de aprendizagem e, especialmente, para sanar algumas dúvidas de pais e professores quanto ao desempenho intelectual dos escolares cegos e de baixa visão.

As necessidades educacionais especiais dos escolares com baixa visão e cegueira, por sua vez, resultaram na adequação das atividades e avaliação em sala de aula; uso de recursos especiais como computador com leitor de tela ou fonte ampliada, máquina braile; adaptação de recursos didáticos: material didático ampliado ou em braile, caderno com pauta ampliada e porta texto. Torna-se importante pontuar que esses alunos participavam apenas como ouvintes em sala de aula.

Os alunos com deficiência visual poderão ter suas necessidades específicas atendidas com pequenas adequaçóes curriculares, utilização de recursos especiais e adaptação dos materiais instrucionais como forma de dar respostas as suas necessidades educacionais especiais.

Este estudo evidenciou a ausência de políticas públicas de atenção à saúde, uma vez que os dados indicam que tanto as crianças indígenas como os próprios professores e pais não tiveram oportunidade de passar por exames oftalmológicos para prevenção da deficiência visual e dos problemas oculares. Observa-se que o direito à saúde para essa população não está sendo concedido conforme os preceitos constitucionais vigentes.

Em relação à educação especial, o estudo revela que, embora haja algumas iniciativas pontuais, o Atendimento Educacional Especializado (AEE) e as informações sobre a avaliação das necessidades específicas e educacionais especiais ainda náo se fazem presentes nas escolas 
indígenas. Foram encontrados escolares sem o AEE, sem acesso à leitura e escrita pelo sistema braile, sem apoio de recursos específicos e adaptaçóes de recursos e materiais didáticos para otimização do processo de aprendizagem. Encontram-se privados do desenvolvimento de todas as possibilidades humanas, bem como da oportunidade de participação e acesso aos bens culturais das comunidades indígenas em que vivem.

Os resultados deste estudo identificaram a existência de nove cegos, dos quais quatro não têm acesso à educação; sete com baixa visão, dos quais três estão fora da escola; e um com deficiência múltipla. Esses alunos gostariam de estar na escola, no entanto, eles e seus familiares não tinham a informação de que cegos poderiam estudar. Esse desconhecimento acerca do direito à educação ocorre devido ao fato de que grande parte da população indígena adulta não foi escolarizada e, muitas vezes, não domina a língua portuguesa.

Consta-se que a história desse povo continua profundamente marcada pela exclusão social, pelo descaso político, manchada pela negação dos direitos fundamentais das pessoas humanas. A efetivação dos direitos sociais fundamentais e a inclusão socioeducacional com igualdade de oportunidade para os escolares indígenas com deficiência visual estão sendo ignoradas pelo poder público, uma vez que a efetivação do direito à educação não envolve apenas o acesso, mas também a participação em todas as atividades, a alfabetização, a qualidade do ensino e também o direito ao AEE como forma de garantir a permanência com sucesso desses alunos no ensino regular.

Essa realidade vivida pelos povos indígenas sinaliza a ausência da articulação entre as diversas áreas da ciência: saúde, educação (políticas públicas e gestão) e Educação Especial. Como nos ensinam os pressupostos do pensamento complexo de Morin (2003, p.43), o qual nos orienta que devemos estar juntos, articular conhecimentos com diferentes fios que se transformam numa coisa só. "Isto é, tudo se entrecruza tudo se entrelaça para formar uma unidade complexa, porém a diversidade do complexo não destrói a variedade da diversidade das complexidades que o teceram. A dificuldade para a inclusão educacional dos escolares indígenas passa por ter que enfrentar a incerteza e a contradição e, ao mesmo tempo, ter que contribuir com a solidariedade dos fenômenos existentes em si.

\section{REFERÊNCIAS}

ALVES, M.R.; KARA-JOSÉ, N. Manual de orientação ao professor: Campanha Nacional de Reabilitação Visual. São Paulo: CBO, MECE, FNDE, 2000.

BRAND, A. O impacto da perda da terra sobre a tradição Kaiowá/Guarani: os difíceis caminhos das palavras. 1997. 350f. Tese (Doutorado em Antropologia) - Faculdade de Filosofia e Ciências Humanas, Pontifícia Universidade Católica do Rio Grande do Sul, Porto Alegre, 1997.

BRASIL. Lei no. 10.172/2001, de 09 de janeiro de 2001. Dispóe sobre o Plano Nacional de Educação. Brasília, DF, 2001.

BRONFENBRENNER, U. A ecologia do desenvolvimento humano. Porto Alegre: Artes Médicas, 1996. BRUNO, M.M.G. Compreendendo a baixa visão. In: Programa de capacitação de recursos humanos do ensino fundamental. Brasília: MEC/SEESP, 2001. 
. Avaliação Educacional de alunos com baixa visão e múltipla na educação infantil: Uma proposta de adaptação e elaboração de instrumentos. 2005. 240f. Tese (Doutorado em Educação) - Faculdade de Filosofia e Ciências, Universidade Estadual Paulista "Júlio de Mesquita Filho", Marília, 2005.

- A construção da escola inclusiva: uma análise das políticas públicas e da prática pedagógica no contexto da educação infantil. In: Ensaios pedagógicos: Programa Educação Inclusiva: direito à diversidade. Brasília: MEC/SEESP, p.173-186, 2007.

CONSELHO BRASILEIRO DE OFTALMOLOGIA. Arquivos brasileiros de oftalmologia, 1998. Disponível em: <http://www.scielo.br/scielo.php?script=sci_serial\&pid=00042749\&lng=en\&nrm=iso>. Acesso em: 20 jan. 2011.

. Arquivos brasileiros de oftalmologia, 2009. Disponível em: <http://www.scielo.br/scielo. php?script=sci_serial\&pid=0004-2749\&lng=en\&nrm=iso>. Acesso em: 20 jan. 2011.

CONSELHO INTERNACIONAL DE OFTALMOLOGIA. Padróes visuais - Aspectos e intervalos da perda da visão. CIO relatório. Sydney, 2002.

ESCALA Optométrica de Snellen, 1862. Disponível em: <http://www.lighthouse.org/espanol/tienda/ articulos>. Acesso em: 29 abr. 2012.

GASPARETTO, M.E.R.F. Visão subnormal em escolas públicas: Conhecimento, opiniāo e conduta de professores e diretores do ensino fundamental. 2001. 380f. Tese (Doutorado em Ciências Médicas) Faculdade de Ciências Médicas, Universidade Estadual de Campinas, Campinas, 2001.

. Visão subnormal: um enfoque educacional. São Paulo: Vetor, 2007.

GRACIANO, J.D. et al. Formação de Horta Caseira na Reserva Indígena de Dourados MS, 2004.

Disponível em: http://www.enapet.ufsc.br/anais/UFGD_AJI_formacao_de_horta _caseira _na_ reserva_indigena_de_Dourados_MS.pdf>. Acesso em: 27 jan. 2011.

HADDAD, M.A.O. Habilitação e reabilitação visual em escolares com baixa visão: aspectos médicosociais. 2006. 282f. Tese (Doutorado em Ciências Médicas) - Faculdade de Medicina, Universidade de São Paulo, São Paulo, 2006.

. SAMPAIO, M.W. Aspectos globais da deficiência visual. In: SAMPAIO, M.W. et al. (Orgs.). Baixa Visão e cegueira: os caminhos para a reabilitação, a educação e a inclusão. Rio de Janeiro: Cultura Médica, Guanabara Koogan, 2010. p. 7-16.

LIGHTHOUSE Letters, 1959. Lighthouse: Nova York. Disponível em: <http://www.lighthouse.org/ espanol/tienda/articulos>. Acesso em: 29 abr. 2012.

LIGHTHOUSE Symbol, 1976. Lighthouse: Nova York. Disponível em: <http://www.lighthouse.org/ espanol/tienda/articulos>. Acesso em: 29 abr. 2012.

LOW Vision. Lighthouse: Nova York, 2005. Disponível em: <http://www.lighthouse.org/espanol/ tienda/articulos>. Acesso em: 30 abr. 2012.

LVRC Distance Visual Acuity Test, 1972. Disponível em: <http://www.vision2020lvrc.hk/load. php?link_id=524>. Acesso em: 29 abr. 2012.

LVRC Bust Card, 1976. <http://www.vision2020lvrc.hk/load.php?link_id=524>. Acesso em: 29 abr. 2012.

MORIN, E. Uma ciência com consciência. Rio de Janeiro: Bertrand Brasil, 2003. 
OMS. Organização Mundial da Saúde. CID - 10 Classificação Estatística Internacional de doença e problemas relacionados à saúde. 9. ed. São Paulo: EDUSP, 2002.

2004.

Organização Mundial da Saúde. Magnitude e causas da deficiência visual. Geneve: OMS,

SAMPAIO, M.W.; HADDAD, M.A.O. Avaliação oftalmológica da pessoa com baixa visão. In:

SAMPAIO, M.W. et al. (Orgs.). Baixa Visão e cegueira: os caminhos para a reabilitação, a educação e a inclusão. Rio de Janeiro: Cultura Médica, Guanabara Koogan, 2010.

SOUZA, V.P.S. Tive fome e não me destes de comer: Socialização e processos educativos de crianças do centro de recuperação nutricional infantil. 2008. 117f. Monografia (Especialização em formação de profissionais da educação) - Faculdade de Educação, Universidade Federal da Grande Dourados, Dourados, 2008.

UNICAMP, Teste de leitura da Unicamp. Campinas: Departamento de Oftalmologia, Setor de Visão Subnormal, Campinas, 1990.

Recebido em: 08/12/2011

Reformulado em: 27/05/2012

Aprovado em: 27/08/2012. 